\title{
TA Treatment of Depression - A Hermeneutic Single-Case Efficacy Design Study - 'Denise'
}

\author{
(C) 2012 Mark Widdowson
}

\begin{abstract}
Hermeneutic Single-Case Efficacy Design (HSCED) is a systematic case study research method involving the cross-examination of mixed method data to generate both plausible arguments that the client changed due to therapy and alternative explanations. The present study uses HSCED to investigate the outcome of short-term TA psychotherapy with a woman with severe depression. The objective of the research was to investigate the effectiveness of short-term TA therapy for the treatment of depression and to explore and identify key aspects of the TA therapy process and associated factors promoting change amongst effective cases. To enhance rigour and to address potential for researcher allegiance, independent psychotherapy researchers have adjudicated the case and offer a verdict on outcome. The conclusion of the adjudicators is that the client changed substantially, and that these changes were substantially due to the effects of therapy.
\end{abstract}

Additional rigour was introduced into the HSCED approach for this $2^{\text {nd }}$ case through the use of a more stringent classification of change, an increased reliable change index score, a higher standard of proof, the use of two teams to develop the affirmative and sceptic cases, and the addition of a third judge.

\section{Key words}

Depression; Hermeneutic Single-Case Efficacy Design; Case Study Research; Transactional Analysis Psychotherapy.

Editor's Note: For the $1^{\text {st }}$ paper in this series, which appeared in IJTAR 3:1, the author provided detailed appendices: the case record, affirmative and sceptic cases, judges' opinions, and various templates including adherence checklists.

\section{Introduction}

This article presents the case of 'Denise', a 46 year old white British female social worker who engaged in short-term TA psychotherapy for the treatment of depression. This article is the second in a series of systematic case studies (Iwakabe and Gazzola, 2009; McLeod, 2010) conducted by the author as part of his doctoral research investigating the process and outcome of (short-term) TA psychotherapy for the treatment of depression. In line with the first case in this series (Widdowson, 2012), the aim of this present case was to use case study methodology to analyse the effectiveness of TA therapy for the treatment of depression and to conduct a detailed analysis regarding the process of therapy.

This present case contributes to the literature on outcomes of TA psychotherapy for treatment of depression. The existing evidence-base supporting use of TA therapy for depression is small, but nevertheless shows TA is a promising intervention. The two main studies within the TA research literature regarding depression are those of Fetsch and Sprinkle (1982), which found short-term TA group therapy to be an effective intervention for men with mild-moderate depression and the first case in this series (Widdowson, 2012) which found short-term individual TA therapy to have been effective in a single-case for the treatment of severe depression. Further supporting evidence comes from the findings of a meta-analysis by Bledsoe and Grote (2006) which found that a group-based approach which integrated TA, CBT and psychoeducation was effective for the treatment of post-partum depression and the recent research conducted by van Rijn, Wild and Moran (2011) which compared short term TA therapy and short-term integrative counselling psychology in primary care settings in the UK and concluded that TA therapy was comparable to 
integrative counselling psychology and using a benchmarking strategy, produced an equivalent recovery rate to $\mathrm{CBT}$.

This present study is contributing to this literature by utilising the replication of method and findings in case study research with clients from a single, clinicallydefined diagnostic category (in this case, people who have depression) to enhance the degree of confidence one can have in the efficacy of short-term TA psychotherapy for the treatment of depression. This present case concludes with some cross-case analysis and aggregation of findings from the first case in this series by identifying similarities between cases and analysis of client factors (moderator variables) and therapeutic processes (mediator variables). It is the replication of findings, and in particular the identification of specific factors in each case which enable the process of generalisation of findings in case study research (Iwakabe and Gazzola, 2009; McLeod, 2010). Generalizations from individual case studies need to be interpreted with caution and need to be made in consideration of the characteristics of each case (Miller, 2011). Further replication of this approach using a heterogeneous sample of clients will enable greater discrimination between factors relating to the client, the therapist and the therapeutic approach that determine outcome.

Replicating the methodology in the previous case in this series, this present case uses Hermeneutic Single-Case Efficacy Design (HSCED) (Elliott, 2001, 2002; Stephen and Elliott, 2011) to 'evaluate the efficacy of psychotherapy on a case by case basis by asking:

- "Did the client change substantially over the course of therapy?

- Is this change substantially due to the effect of the therapy?

- What factors (including mediator and moderator variables) may be responsible for the change?" (Stephen and Elliott, 2011; 231)

The HSCED process involves the development of the affirmative and sceptic arguments and a crossexamination of the evidence of the case by independent psychotherapy researchers acting as judges to determine the outcome of the case and the salient features of the therapy which contributed to the client's changes and to explore alternative conclusions and possibilities regarding the process and outcome of the case. 'We argue that at the heart of the adjudicated case study approach is the requirement to test or "cross-examine" the evidence. The proposition is that if an alternative interpretation of the evidence is experienced as plausible by the judges or jurors, then the likelihood that the claim is valid must be diminished' (Stephen and Elliott, 2011; 234). The use of independent psychotherapy researchers - researchers who use a different theoretical approach to the one being investigated - in the adjudication process helps to reduce the risk of researcher allegiance and bias influencing the findings of the research and contributes to the robustness and also the impartiality of the conclusions.

The HSCED procedure has been described in Widdowson (2012) and will not be described in detail in this introduction, although following on from the first case in this series and in conjunction with discussions with Robert Elliott, the originator of this method and wider developments in the use of HSCED method, a greater degree of stringency has been applied to this present case to strengthen the robustness of the method and the findings.

The first of these is the use of clinically significant change, rather than 'change below level of caseness' as applied in the case of 'Peter'. The second relates to the increase in reliable change index (Jacobson and Truax, 1991) score on the Personal Questionnaire scores from 0.53 in the case of 'Peter' to 1.0 in this present case. The third change relates to the standard of proof required in this present study. In line with developments in HSCED method and congruent with the quasi-legal framework used in HSCED, the standard of proof required has been heuristically set at between 'beyond reasonable doubt' (equivalent to a 95\% probability) and 'balance of probabilities' (equivalent to $>50 \%$ probability) at 'clear and convincing evidence' which has been defined by Stephen and Elliott (2011) as being equivalent to $80 \%$ probability. Despite this increased stringency in the present study, if retrospectively applied to the case of 'Peter' (Widdowson, 2012) the findings in that case remain unchanged.

An additional change to this present study is the use of two separate teams to develop the affirmative and sceptic cases. One of the objectives of this case series has been to encourage the use of case study methodology within the TA community, and to further this process, the author conducted a 'case study research analysis workshop' attended by TA psychotherapy trainees to give them real, practical experience of participating in the research analysis process. The trainees were given an introductory lecture to the HSCED method and reviewed several cases and formulated the affirmative and sceptic cases (see below).

The final change in this present case is the use of three instead of two judges. It was assumed that determining the overall verdict of three judges would facilitate the drawing of conclusions in the case of disagreement over fine details between judges or by introducing the principle of balance of verdict by swing in majority or from generating the mean of results. 
One advantage of the compilation of the 'rich case record' used in systematic case study methodology (McLeod, 2010) is that it provides a detailed description of the case, its context and its unique features which can facilitate the drawing of conclusions regarding the effective ingredients which produced a therapeutic outcome. The use of the rich case record in this study utilises both the therapist's and the client's voices, by integrating the therapist's notes and the client's comments in their post-session qualitative questionnaires and their Change Interview (the case record is available from the researcher, on request) and quantitative data from client self-report outcome measures. One feature of the case record is the emphasis placed on the client's comments, reflections and views. Thus, the use of the client as the 'primary witness' is congruent with a humanistic approach which values the client and does not create an unhelpful hierarchy which over-values the therapist's account.

\section{Method}

\section{Participants}

\section{Client}

Denise was a 46 year old social worker presenting with her third episode of depression which had been diagnosed by her family doctor. At the time of entry into therapy she was on sick leave from work due to her depression and with her doctor's support had opted for talking therapy instead of antidepressant medication. She had previously had two periods of brief therapy; the first one over fifteen years ago at the time of her first depressive episode, and the second shortly after the sudden death in a car accident of her husband ten years earlier, which she had found to be helpful in dealing with her bereavement. This present episode of depression was the longest and the most severe she had experienced. She was single and lived with her two teenage children, who she reported having a generally good relationship with.

Although she was on sick leave at the time of starting therapy, Denise was well-groomed in appearance. Despite this she stated that she was not taking good care of herself- she was not eating well, had stopped exercising and was not listening to her body's signals, for example by not resting when tired. She described feeling a sense of despair and emptiness and felt like she was 'going through the motions' of life- unengaged and disinterested. She described feeling continually tired, although she did wonder whether this was due to her underactive thyroid (which she was taking medication for) or connected to feeling depressed. She described that she was finding getting out of bed in the morning a struggle and had gradually withdrawn from socialising.

Denise had always enjoyed her job but recently was finding the demands of her role increasingly difficult to manage, and in particular was struggling to deal with the hostility which she often received from service users. Denise was also doing a part time Master's degree in social work which she had previously enjoyed but was afraid she would not be able to manage the demands of the course. As is often the case in people who work in helping professions, Denise was frequently called upon by members of both her immediate and extended family to sort problems out and felt that she was taken for granted.

Denise was an intelligent and articulate woman. She had been introduced to Transactional Analysis by a colleague, and after reading a book about TA she actively sought out a TA therapist working in private practice. She had attended a one year course in counselling skills two years previously, and was familiar with the principles of therapy. Throughout the course of her therapy she continued to read about TA, and to apply TA theory to assist her self-understanding and support her change process.

At her initial meeting with her therapist, the therapist ascertained that she did not meet any excluding criteria for participation in the study and conducted a brief clinical diagnostic interview to confirm diagnosis of major depressive disorder based on DSM-IV diagnostic criteria (APA, 1994). She was screened using CORE$\mathrm{OM}$ and BDI-II and met the criteria for 'caseness' and inclusion in the study. Denise's clinical score using CORE-OM was 21.1, indicating moderate levels of distress and functional impairment and her BDI-II score was 33 , indicating severe depression.

The therapist gave Denise an information pack about the study, and several days later she contacted the therapist to say that she would like to participate in the research. She completed an informed consent form, although did not give consent for audio recordings of sessions to be made.

At the end of therapy, she once again completed an informed consent form and agreed for her case to be written up for the purposes of research and teaching and for publication. She was given the 'rich case record' when completed for checking and gave consent for the document to be used and agreed that it was an accurate representation of her therapy. She was seen in a naturalistic therapy protocol for a period of sixteen weekly individual sessions.

\section{Therapist and Treatment}

The therapist in this case was David, a male white British therapist who was a Certified Transactional Analyst (Psychotherapy) with over five years postqualifying experience and a Teaching and Supervising Transactional Analyst (Psychotherapy). He had approximately one hour of monthly supervision on this case with an experienced Teaching and Supervising Transactional Analyst. For reasons of confidentiality 
and to preserve the client's anonymity, the identity of the therapist has been obscured. David was involved in the development of the rich case record, and the construction of the affirmative and sceptic arguments.

The therapist provided short-term TA therapy which worked to the therapeutic tasks shown in the Adherence Checklists (Widdowson, 2012: App 7\&8). As the research was a naturalistic study, the therapist conducted the therapy in line with their usual practice and procedures and created an individualised approach to match the client's needs. Essentially, the therapy process began with an initial alliance formation/ diagnostic/ contracting phase which involved identification of Denise's key script themes, racket system, internal dialogue (ego states/ structural analysis) and key interpersonal patterns which reinforced her script.

The second phase of the therapy (sessions 4-16) involved revisiting painful past experiences from the client's history and expressing associated emotions (deconfusion) and validation and normalisation of these emotional reactions. This also involved re-evaluating the significance of these events in the formation of the client's script, and challenging her discounting of self and her self-critical negative internal dialogue (ego states) and replacing this with a more soothing nurturing inner dialogue. This phase also included substantial exploration of current interpersonal patterns (transactions, stroking patterns, games), the client's interpretation of current interactions and how these were reinforcing the client's script ,and work which focused on changing these patterns. A full account of the therapy is contained in the rich case record which is available on request from the author.

\section{Analysis Team}

The analysis team who generated the affirmative and sceptic arguments was comprised of 7 students in training for the Certified Transactional Analyst (Psychotherapy) qualification, who attended a full-day case study research analysis workshop. All postfoundation year trainees at the training institute involved were sent an e-mail invitation to attend and participants in the analysis self-selected. The workshop was intended to provide experiential learning of case study research analysis and was co-facilitated by the author and Katie Banks, Certified Transactional Analyst (Psychotherapy). (Ms Banks had participated in the analysis of the case of 'Peter'). Participants had been sent copies of the rich case records, plus an article describing the HSCED method one week prior to the workshop. The workshop commenced with a one-hour presentation on the HSCED method, following which the students read the rich case record and were split into two groups; one group formed the affirmative case, and the second group formed the sceptic case. Each group was facilitated by one of the co-facilitators who assisted the group members in developing their arguments.

Judges

The three independent judges were selected on the basis that they were therapists from another modality, and had experience of participating in a HSCED investigation. The judges were recommended to the author by Robert Elliott, the originator of the HSCED approach and none of the judges were previously known to the researcher. The judges were Jane Balmforth, a person-centred counsellor working in a $\mathrm{HE}$ college who is currently doing a $\mathrm{PhD}$ in Counselling at the University of Strathclyde studying significant client disclosures in therapy; Anja Rutten, a counsellor and lecturer in counselling and psychology at Staffordshire University who is currently doing a PhD with the University of Strathclyde investigating person-centred/ emotion-focused therapy for people with Asperger's syndrome; and Susan Stephen, a Person-Centred BACP accredited counsellor working in private practice who has a background in law and a master's degree in counselling, and who also acted as a judge in the case of 'Peter' (see Widdowson, 2012).

\section{Measures}

In line with procedures and guidelines for the development of a systematic case study (Iwakabe and Gazzola, 2009; McLeod, 2010), multiple tools were used to build up a complex and detailed collection of quantitative and qualitative data and to assist in the compilation of the rich case record.

(The section below has been reproduced from Widdowson, 2012 as all measures and the procedure for administration of these was identical to the previously reported case of 'Peter')

\section{Quantitative Outcome Measures}

Two standardised self-report outcome measures were selected to measure target symptoms (Beck Depression Inventory- BDI-II) (Beck et al. 1996) and global distress/ functional impairment (CORE-OM) (Barkham et al., 2006). These were administered before the first session, and at sessions 8 (mid-way through therapy) and 16 (end of therapy). These measures were also administered at the one-month, three-month and sixmonth follow up periods. These measures were evaluated according to clinical significance (client moved into a non-clinical range score) and Reliable Change Index (Jacobson and Truax, 1991) (nonclinically significant change). See Table 1 for Reliable Change Index $(\mathrm{RCl})$ values for each measure.

\section{Weekly Outcome Measures}

In order to measure on-going progress, and to facilitate the identification of key therapeutic events which produce significant change, two weekly outcome measures were administered prior to the start of each session. 
These were CORE-10 (Connell \& Barkham 2007), a ten item shortened version of the CORE-OM which has good correlation with CORE-OM scores and can be used to monitor change. The second measure was the simplified Personal Questionnaire (PQ) (Elliott, et al, 1999). This is a client-generated measure in which clients specify the problems they are wanting to address in their therapy, and rate their problems according to how distressing they are finding each problem. The $P Q$ was also administered at each of the three follow-up intervals.

\section{Qualitative Outcome Measurement}

Qualitative outcome data was collected one month after the conclusion of the therapy. The client was interviewed using the Change Interview protocol (Elliott, 2001) - a semi-structured qualitative change measure which invites the client to explain how they feel they have changed since starting therapy, how they think these changes came about, what they felt was helpful or hindering in the therapy, and what changes they feel they still need to make. As part of this, the client identifies key changes they have made and indicates using a five-point scale whether they expected these changes, how likely these changes would have been without therapy, and how important they feel these changes to be.

\section{Qualitative Data about Helpful Aspects of Therapy}

In order to gain data regarding specific events or aspects of the therapy the client found useful, the client completed the Helpful Aspects of Therapy (HAT) (Llewelyn, 1988) at the end of each session. The HAT asks the client to describe both the most and least helpful aspects of the therapy session and to rate the helpfulness/ unhelpfulness of the session.

\section{Therapist Notes}

The therapist also completed a structured session notes form at the end of each session. The therapist provided a brief description of the session and key issues, therapy process, the theories and interventions they used and indicated how helpful they felt the session was for the client.

\section{Adherence}

The therapist also completed a twelve-item adherence form at the end of each session, rating the session on a sixpoint scale. The therapist's supervisor also rated the therapist's work using the same form to verify therapist competence and adherence in providing identifiably TA therapy. (Widdowson, 2012: 5-6)

\section{HSCED Analysis Procedure}

(Note: this section has also been reproduced from Widdowson, 2012 as the guidelines for the development of both the affirmative and sceptic cases are identical to those for the previous case)

\section{Affirmative Case}

The affirmative case is built by identifying positive and convincing evidence to support a claim that the client changed and that these changes primarily came about as a result of therapy. In line with HSCED procedure, to make a convincing case that the client changed positively and as a result of therapy, the affirmative case must be built by identifying evidence for at least two of the following:

1. changes in stable problems: client experiences changes in long-standing problems

2. retrospective attribution: client attributes therapy as being the primary cause of their changes

3. outcome to process mapping: 'Content of the post-therapy qualitative or quantitative changes plausibly matches specific events, aspects, or processes within therapy' (Elliott et. al, 2009; 548)

4. event-shift sequences: links between 'client reliable gains' in the PQ scores and 'significant within therapy' events

\section{Sceptic Case}

The sceptic case is the development of a good-faith argument to cast doubt on the affirmative case that the client changed and that these changes are attributable to therapy. It does this by identifying flaws in the argument and presenting alternative explanations that could account for all or most of the change reported. Evidence is collected to support eight possible non-therapy explanations. These are:

irrelevant

1. Apparent changes are negative or

2. Apparent changes are due to measurement or other statistical error

3. Apparent changes are due to relational factors (the client feeling appreciative of, or expressing their liking of the therapist or an attempt to please the therapist or researcher) (note, this is a term used in the HSCED approach and does not refer to the impact of the therapeutic relationship as a vehicle for change and relates to factors not directly within the therapy process. The reader is invited to notice the different ways that 'relational' is used within this report, which include this criteria, the therapeutic relationship and a relational approach to therapy)

4. Apparent changes are due to the client conforming to cultural or personal expectancies of change in therapy

5. Improvement is due to resolution of a temporary state of distress or natural recovery

6. Improvement is due to extra-therapy factors (such as change in job or personal relationships etc)

7. Improvement is due to biological factors (such as medication or herbal remedies) 
the research

8. Improvement is due to effects of being in

Once the sceptic case had been presented, the affirmative team developed rebuttals to the sceptic case. The sceptic team then developed further rebuttals to the affirmative rebuttals, thus providing a detailed and balanced argument.

\section{Adjudication Procedure}

The rich case record and the affirmative and sceptic cases and rebuttals were then sent to the independent judges for adjudication. The judges were asked to examine the evidence and provide their verdict as to whether the case was a clearly good outcome case, a mixed outcome case, or a poor outcome case; to what extent the client had changed and to what extent these changes had been a result of therapy; and to indicate which aspects of the affirmative and sceptic arguments had informed their position. The judges were also asked to comment on what factors in the therapy did they consider to have been helpful and which characteristics about the client did they think had contributed to the changes. (Widdowson, 2012: 6)

\section{Results}

\section{Quantitative Outcome Data}

Denise's quantitative outcome data is presented in Table 1. As can be seen, all of Denise's initial scores were well within clinical ranges and substantially higher than the caseness cut-off for inclusion in the study. Her BDI-II score at entry into therapy was 33 , indicating severe depression and her CORE-OM score was 21.1, indicating moderate levels of global distress and functional impairment. Denise's BDI-II score had demonstrated reliable change by session 8 , and was maintained at session 16 , then continuing to improve to clinically significant levels of change at one-month follow up and maintained throughout the follow-up period. It is noteworthy at this point to mention that Denise experienced two bereavements in the latter half of her therapy- a factor which the affirmative team discussed in their analysis of the case. Denise's CORE scores had attained clinically significant change by session 8, and continued to improve through the end of therapy (with some minor deterioration at the time of the bereavements) and during the follow-up period. Denise's PQ scores showed steady improvement throughout therapy, achieving clinically significant change by the end of therapy and showing continued improvement throughout follow-up.

\section{Qualitative Process Data}

Denise completed a HAT form at the end of fifteen of the sessions, indicating what had been helpful or hindering/unhelpful in the session. She identified at least one helpful event on each of these forms, and did not identify any hindering or unhelpful events during the therapy. The majority of the helpful events Denise identified related to feeling safe and accepted and other aspects of the therapeutic relationship, to increased insight into her intrapsychic and interpersonal process and also to expressing previously unexpressed emotions which related to the therapist's focus on deconfusion. Examples include:

In session 4: 'Getting in touch with my feelings. Feeling my feelings and knowing that they need to be acknowledged and allowed to be completed over time. Space in the conversation, authenticity of the therapist. Feeling safe in the environment with my therapist. I got acknowledgement of myself and permission to work through what I need to do and to take as long as it takes' (rated 8- 'greatly helpful')

In session 6; 'In this session it was the feeling of being in a safe environment in which I knew I was not going to be judged which allowed me to open up to speak about something I had never even alluded to anyone else about. Knowing that my therapist was experienced enough to guide me through the memories and that I was reassured that they could be revisited as appropriate. Also the invitation to explore the subject made me feel reassured that I could speak about it. (rated 8- 'greatly helpful')

Exploration of my family dynamics and the dichotomy of being seen by my family when they need me to do something.' (rated 9 - 'extremely helpful')

In session 12: 'Discussion which involved the question 'what makes therapy work for you?' My answers include; being asked to really look at myself and how I function. Taking cognizance of the games I play, of my script. Knowing I am accepted as an intelligent human being who can think for myself and I am important in the whole process, as in I can make my own decision and be responsible for the consequences. What I got out of it is the knowledge and reassurance that I am OK. I'm an equal in this journey and my opinions and thoughts are valid. Learning how to look out for and accept the positives in my behavior. (rated 8 - 'greatly helpful')

Being able to feel joy and sadness in the same therapeutic hour without fear that the latter would detract from the former. Also facing up to my grief and knowing I can revisit this whenever I want to safely. (rated 9 - 'extremely helpful')

\section{Qualitative Outcome Data}

In the Change Interview which took place at the onemonth follow-up, Denise identified ten changes which had occurred since starting therapy. The changes are listed in Table 2. These changes primarily related to an increase in her self-esteem and self-confidence. One change related to the development of an optimistic outlook and another change clearly related to changes in how she interacts with others. 
Table 1: Denise's Quantitative Outcome Data

\begin{tabular}{llll} 
& Beck Depression Inventory-II & CORE-OM & $\begin{array}{c}\text { Personal Questionnaire } \\
\text { (mean score) }\end{array}$ \\
\hline Clinical cut-off & 10 & 10 & 3.00 \\
\hline Caseness cut-off & 16 & 15 & 3.50 \\
\hline Reliable Change Index & 5.78 & 4.8 & 1.00 \\
\hline Pre-Therapy & $\mathbf{3 3}$ & $\mathbf{2 1 . 1}$ & $\mathbf{4 . 5}$ \\
\hline Session 8 & $\mathbf{1 7 ( + )}$ & $\mathbf{1 3 . 8 ( + + )}$ & 3.8 \\
\hline Session 16 & $\mathbf{1 7 ( + )}$ & $7(++)$ & $3.0(++)$ \\
\hline 1 month Follow-up & $7(++)$ & $4(++)$ & $2.0(++)$ \\
\hline 3 month Follow-up & $8(++)$ & $7(++)$ & $2.1(++)$ \\
\hline 6 month Follow-up & $1(++)$ & $2(++)$ & $1.6(++)$ \\
\hline
\end{tabular}

Note: Values in bold italic are within clinical range. + indicates Reliable Change, ++ indicates change to below 'caseness' level.

Figure 1: Weekly and Follow-Up CORE-10 scores (clinical significance 10)

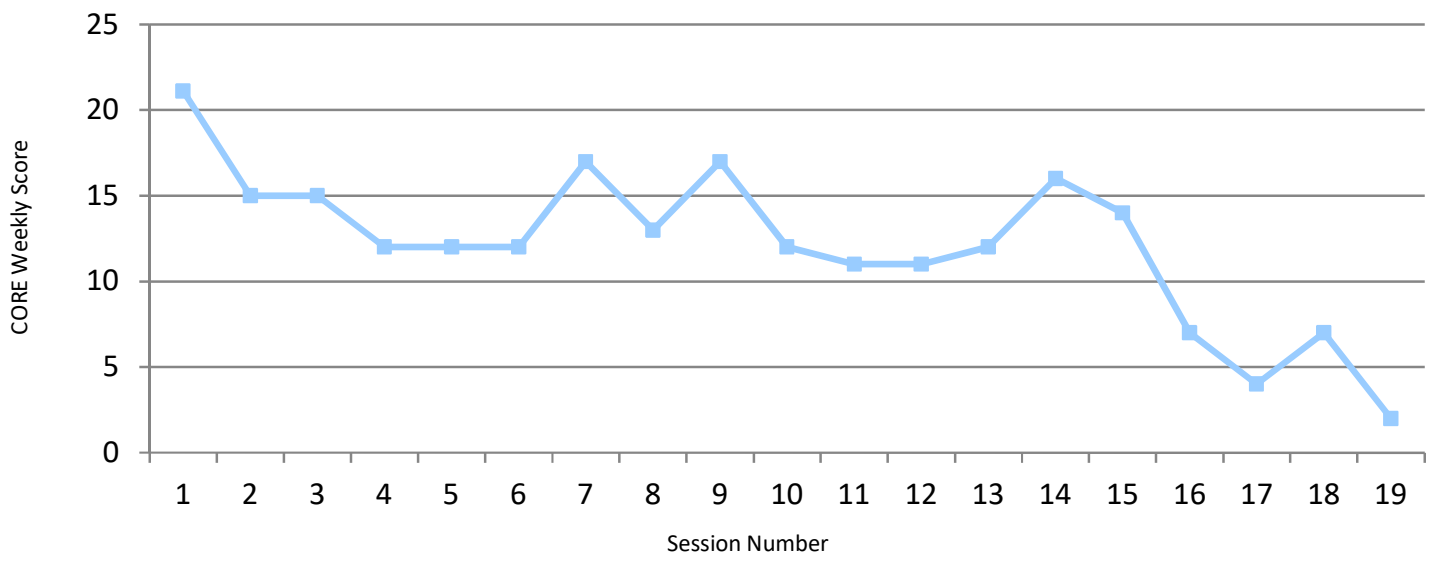

Figure 2: Weekly and Follow-Up mean PQ scores (clinical significance 3)

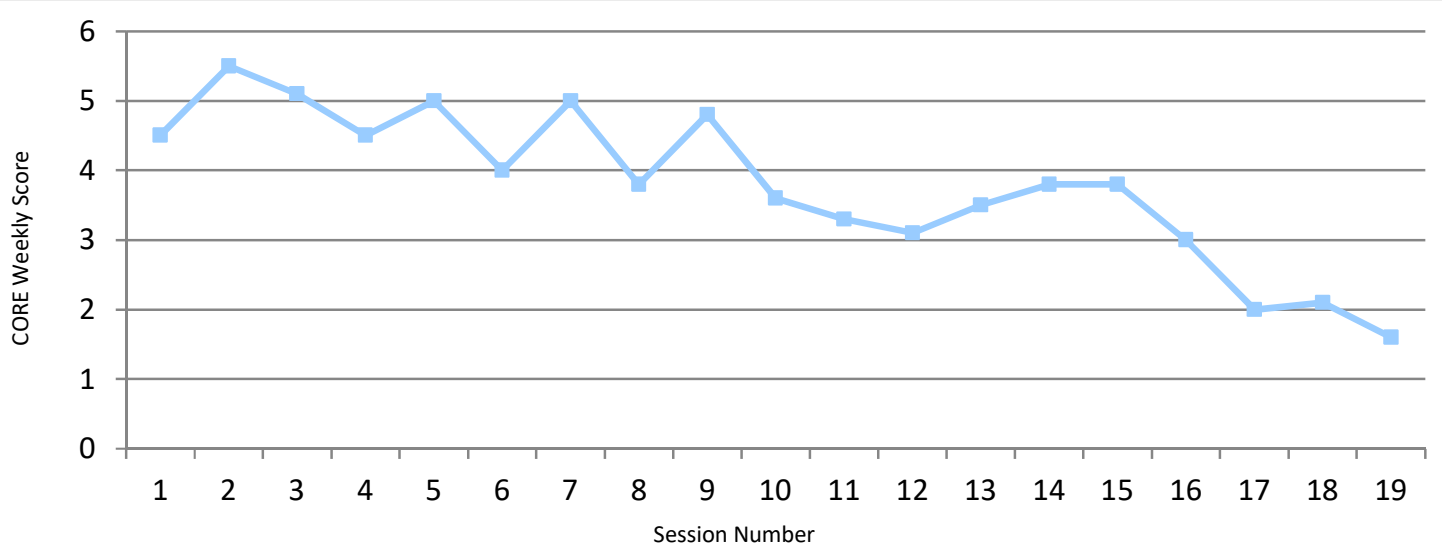


Table 2: Denise's changes as identified in post-therapy Change Interview

\begin{tabular}{|c|c|c|c|}
\hline 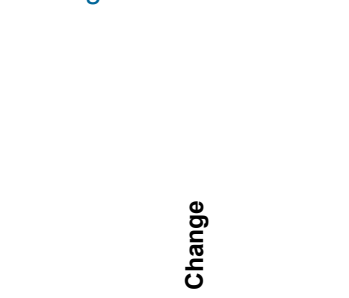 & 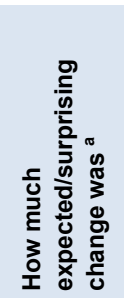 & 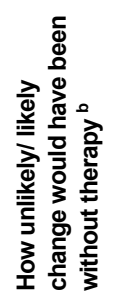 & 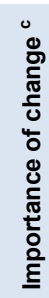 \\
\hline Decision Making & 1 & 1 & 5 \\
\hline Confidence in my abilities & 3 & 1 & 5 \\
\hline Confidence in myself & 5 & 1 & 5 \\
\hline 'Core Strength' & 1 & 1 & 5 \\
\hline Giving myself persmission & 3 & 1 & 5 \\
\hline Improved Body Image & 5 & 1 & 5 \\
\hline I feel happier in myself & 1 & 1 & 5 \\
\hline Optimism & 5 & 1 & 5 \\
\hline $\begin{array}{l}\text { I feel more equal and less } \\
\text { adapted in my relationships }\end{array}$ & 5 & 1 & 5 \\
\hline I now see myself as important & 5 & 1 & 5 \\
\hline
\end{tabular}

a The rating is on a scale from 1 to 5 ;

$1=$ expected, $3=$ neither, $5=$ surprising

${ }^{\mathrm{b}}$ The rating is on a scale from 1 to 5 ;

$1=$ unlikely, $3=$ =neither, $5=$ likely

${ }^{\mathrm{C}}$ The rating is on a scale from 1 to 5 ;

$1=$ slightly, 3 = moderately, $4=$ very, $5=$ extremely

\section{Affirmative Case}

The affirmative team argued that there were four main lines of argument which provided clear and compelling evidence that Denise had changed substantially and that these changes had been due to therapy. The first line of evidence put forward was the changes in Denise's quantitative measures- by session sixteen she had achieved clinically significant change on the CORE$\mathrm{OM}$ and $\mathrm{PQ}$ and had achieved reliable change on her BDI-II scores. The affirmative team put forward the argument that Denise was still recovering from two bereavements and that her score on BDI-II at the end of therapy was likely to be associated with the impact of these bereavements and cited her improvement at the one-month follow up as evidence of this. At the one month follow-up, Denise showed clinically significant change on all three measures which was sustained throughout the remainder of the follow-up period. This was considered to be particularly compelling given the initial severity of Denise's depression. The affirmative team also highlighted that the items on Denise's PQ had all been long-standing problems and that these appeared to have been resolved during therapy and that this improvement had been maintained, suggesting she had experienced internal restructuring and resolution of factors which contributed to her depression. Evidence from Denise's Change Interview was also cited, including the development of a positive and optimistic outlook on life and her descriptions of significant changes made in her day-to-day life such as changes in her self-esteem, relationships, working patterns, self-care and financial matters.

The second line of evidence related to Denise's clear and unequivocal retrospective attribution that all of her changes were unlikely to have come about without therapy. The third line of evidence related to how there appeared to be convincing links between the therapy process (as described in the therapist's account and Denise's responses on the HAT forms) and the ten changes which Denise identified in her Change Interview. Finally, the affirmative team noted that there was clear evidence of significant event-shift sequences with reliable change (as measured by improvements on $P Q$ and CORE scores) demonstrated after sessions seven, nine and fifteen.

\section{Sceptic Case}

The sceptic team considered that there was reason to believe that Denise's problems were more reactive to external events than her Change Interview might suggest and that her improvements could be explained by extra-therapy changes, such as changes in her working conditions and natural recovery from bereavement. The sceptic team also highlighted that Denise's description of the therapy and therapist was extremely positive- despite her reporting feelings frustrated at several points in the therapy suggesting that (social) relational factors may be influencing her report of the therapy. Additionally, the sceptic team considered that there was evidence that expectancy factors may have led Denise to overestimate the magnitude of her change. Associated with both relational and expectancy factors the sceptic team cited Denise's tendency to please other people as potentially casting doubt on the attribution of change to the therapy.

\section{Affirmative Rebuttal}

The affirmative rebuttal argued that although there had been many external changes in Denise's circumstances, she attributed these to changes she made in therapy and noted that Denise's BDI-II scores at the one-month follow-up suggested a rapid recovery from her bereavements thus indicating that deep changes had taken place in how she responded to stressful events. The affirmative team refuted the sceptic team's argument relating to relational factors, 
citing Denise's acknowledgment of her frustration at times during therapy as providing a balanced picture which did not suggest an overly positive view of the therapy process and that Denise's subsequent reflection on these occasions demonstrated that she had found these events to be therapeutic.

The affirmative team also refuted the sceptic argument of expectancy factors by considering that Denise's active selection of the type of therapy and the therapist had been the positive choice of an informed and intelligent woman who had carefully made these choices based on a clear appraisal and fairly sophisticated grasp of what the therapy might involve. Linked to this, the affirmative team put forward the view that there was strong evidence that Denise's therapy had been carefully implemented and of being linked to a clear and consistent case formulation and treatment plan throughout. Finally, the affirmative team highlighted that Denise's changes on quantitative and qualitative outcome measures provided a consistent, clear and compelling picture of substantial and lasting global changes.

\section{Sceptic Rebuttal}

The sceptic rebuttal included the view that Denise's description of the change process had been vague and lacking in detail of specific change events in therapy. Linked to this, they put forward that argument that extratherapy factors may have played a much larger role in Denise's improvement than her attributions of change in her Change Interview. The sceptic rebuttal also highlighted Denise's tendency towards not trusting her own abilities, combined with a tendency towards pleasing others would make her highly pre-disposed towards underestimating her own contribution towards positive change and overestimating the influence of her therapist and the therapy.

\section{Adjudication}

The three judges independently reviewed the case materials and produced their reports regarding their verdicts on the case, citing the evidence which had influenced their opinions and describing the factors they considered to have been significant in this case. The judges' verdicts and a mean score of all three judges' conclusions are presented in Table 3. To summarise, the judges concluded that Denise had experienced clinically significant change and had changed substantially and that these changes were substantially due to therapy.

Summary of opinions regarding how the judges would categorise this case

(Clearly good outcome - problem completely solved, Mixed outcome - problem not completely solved, Negative/ Poor Outcome)
There was unanimous verdict of the judges that the case was a clearly good outcome case, with a mean certainty of $86 \%$. The judges considered that the combination of quantitative outcome data showing clinically significant change which was maintained throughout follow-up and the quantitative outcome data from the Change Interview provided convincing evidence that this was a clearly good outcome case, although the judges noted that external factors in Denise's life had probably had an impact in terms of reduced gains in the second half of therapy.

Summary of opinions regarding the extent to which the client had changed

Once again, there was a unanimous verdict of the judges that Denise had changed substantially, with all three judges concluding that the client's changes had been in the $80 \%$ range. The judges varied slightly in their level of confidence in this conclusion, although the mean certainty level was $80 \%$.

Summary of opinions as to whether the changes were due to the therapy

The judges were unanimous in their conclusion that the changes experienced by Denise were substantially $(80 \%)$ due to the effects of therapy. There was some variation in their degree of certainty about this, although the mean certainty level was also $80 \%$. Judges $A$ and $B$ rejected the sceptic claims that Denise's improvement could be accounted for as an attempt to please her therapist and/or due to expectancy factors. To support their rejection of these arguments, they cited Denise's honest account of her frustrations in therapy, her surprise at many of her changes, the changes evident by the outcome measures, her substantial life changes and her achievement of her therapy goals as evidence of clearly positive outcome which could not be accounted for by the sceptic arguments.

Furthermore, judges A and B rejected the sceptic claims that Denise's account of the therapy was vague and felt that on the contrary, Denise has provided a detailed account of the therapy process and that her use of TA language indicated that she had deeply integrated these changes. Judge $\mathrm{C}$, however was somewhat persuaded by the sceptic argument that there may be evidence of some 'pleasing' of the therapist or researcher, in view of the fact that Denise's reports contained uniformly positive comments about the therapy and the therapist.

\section{Mediator factors}

The judges were asked to provide their opinion on which therapist characteristics and therapeutic factors had been most helpful in generating change. The judges agreed that the empathic, non-judgmental and encouraging stance of the therapist had been important 


\begin{tabular}{|c|c|c|c|c|}
\hline & Judge A & Judge B & Judge C & Median/Mean \\
\hline \multicolumn{5}{|l|}{ 1. How would you categorise this case? How certain are you? } \\
\hline 1a. Clearly good outcome (problem completely solved) & $100 \%$ & $80 \%$ & $80 \%$ & $86 \%$ \\
\hline 1b. Mixed Outcome (problem not completely solved) & $0 \%$ & $0 \%$ & $0 \%$ & $0 \%$ \\
\hline 1c. Negative/Poor Outcome & $0 \%$ & $0 \%$ & $0 \%$ & $0 \%$ \\
\hline 2. To what extent did the client change over the course of therapy? & $\begin{array}{c}80 \% \\
\text { Substantially }\end{array}$ & $\begin{array}{c}80 \% \\
\text { Substantially }\end{array}$ & $\begin{array}{c}80 \% \\
\text { Substantially }\end{array}$ & $\begin{array}{c}80 \% \\
\text { Substantially }\end{array}$ \\
\hline 2a. How certain are you? & $100 \%$ & $80 \%$ & $60 \%$ & $80 \%$ \\
\hline 3. To what extent is this change due to therapy? & $\begin{array}{c}80 \% \\
\text { Substantially }\end{array}$ & $\begin{array}{c}80 \% \\
\text { Substantially }\end{array}$ & $\begin{array}{c}80 \% \\
\text { Substantially }\end{array}$ & $\begin{array}{c}80 \% \\
\text { Substantially }\end{array}$ \\
\hline 3a. How certain are you? & $100 \%$ & $80 \%$ & $60 \%$ & $80 \%$ \\
\hline
\end{tabular}

in this case. The judges also agreed that the therapist's willingness to provide a rationale or use theory to explain and support the therapy and assist Denise in making links with and coming to terms with her past had also been important. Furthermore, judges $A$ and $B$ agreed that the therapist's focus on Denise's script and both their continued challenging of her script, an attentiveness to how it might be manifesting in the therapy and avoidance of unhelpful transference enactments of her script had also been a significant factor.

\section{Moderator factors}

The judges were asked to provide their opinion on which personal characteristics and resources of the client enabled the client to make best use of the therapy and enhanced the therapeutic process. All judges agreed that Denise's sense of hopefulness at the outset of therapy was an important factor. The judges also agreed that the fact that Denise was well-informed about both therapy and in particular, TA therapy had also been significant as had her making a clear and informed decision in choosing the right therapist. It was acknowledged that she was clearly well-motivated and had a number of clear goals for the therapy and a degree of insight from the outset and that these too had been important factors. Denise's courageousness and willingness to address difficult and painful material (e.g. sexual abuse) and her continued attempts to integrate the insights gained in therapy into her everyday life was also identified as a key factor.

Judge A identified Denise's willingness to accept her therapist's challenges and persist with finding her own answers to her problems had also been important.

\section{Discussion}

Once again, replicating the findings in the case of 'Peter', TA psychotherapy was a successful treatment for severe depression. These results also seem to support the conclusions of the meta-analysis of Cuijpers et al (2011) that initial severity of depression did not appear to negatively impact on the efficacy of psychotherapy, however do not support the conclusions of van Rijn et al (2011) that severity of initial symptoms negatively impacted on outcomes and therefore further research is warranted to investigate the relationship between initial severity and other factors which may contribute to outcome.

This positive replication of the effectiveness of shortterm TA therapy for the treatment of depression in a second systematic case study clearly indicates that TA psychotherapy shows considerable promise as a psychological therapy for the treatment of depression and is another step forward to the recognition of TA as an evidence-based therapy.

In line with much previous research, the quality of the therapeutic relationship appeared to be significant to the outcome. A TA perspective on important aspects of the therapeutic relationship appear to be that it was characterised by an 'I'm OK- You're OK' style of relating, therapist permissiveness and nurturing which emphasised the client's autonomy and capacity to change combined with careful attention not to inadvertently reinforce the client's script beliefs in the therapy process. Furthermore, also in line with existing research and the previously published case of 'Peter' from this present series, the impact of client hope and expectations (Constantino, et al. 2011), motivation 
(Zuroff, et al. 2007) and client preferences (Swift, et al. 2011) appear to have been significant factors contributing towards the positive outcome in this case. Additional features which this case shares with the case of Peter include the therapist's clear case formulation and willingness to explore theoretical explanation with the client as being helpful, the courageousness of client to commit to the process and push themselves through difficult and painful therapy processes.

Similar to the case of Peter, this present case did not appear to identify specific mechanisms of action or interventions/ therapy episodes which produced significant change and therefore further research is indicated which would explore and identify effective therapeutic procedures, in addition to therapeutic relationship factors.

\section{Limitations}

A potential limitation of this case is that the researcher was either the current or former course tutor of the members of the analysis team, and this may have inadvertently influenced their responses. Despite the thoroughness of their arguments, it is also possible that their relative inexperience may have limited their arguments. The possibility of researcher bias is one which needs to be accounted for in the findings of this present study, although the use of three independent psychotherapy researchers acting as judges was used as a strategy to reduce this risk.

\section{Conclusion}

The conclusions of the judges are that Denise changed substantially and that these changes were substantially due to the effects of therapy. Denise attained clinically significant change on all three quantitative outcome measures and had sustained her improvement throughout follow-up. Her change interview responses provided a clear and compelling argument regarding the magnitude and breadth of her changes and that these changes were primarily due to the effects of therapy.

Although the gains in the second half of the therapy were somewhat limited, it would appear that this was due to the impact of extra-therapy factors, in particular bereavement and that once the acute grief phase had passed, Denise continued to improve, suggesting that the changes were deeply integrated and were selfmaintaining. The importance of the therapeutic relationship is once again reaffirmed as crucial in promoting therapeutic change and there is preliminary evidence from this case and the case of Peter to suggest that the use of TA for case formulation and in providing rationale/ explanation for the client is an effective approach when matched to the client's preferences and life script.
This present case strengthens the argument put forward in the case of Peter that short-term TA psychotherapy clearly has promise as a treatment for depression. Furthermore, it would appear that TA psychotherapy has promise as a treatment with severe depression with clients who are motivated, actively engaged in the treatment process and who feel 'well-matched' to their therapist.

Mark Widdowson, Teaching and Supervising Transactional Analyst (Psychotherapy), Associate Director, The Berne Institute, Ph D student, University of Leicester, can be contacted on: mark.widdowson1@btopenworld.com

The author wishes to thank the members of the analysis team: Jane Bernard, Isabel Burns, Phil Crawley, Mike Day, David Harford, Colin Kerr and Owen Vaughan. Particular thanks also are due to Katie Banks for her invaluable contribution.

The author also acknowledges with grateful thanks the support of Physis Training in Edinburgh, which provided the venue and participants for the workshop at which the affirmative and sceptic cases were developed.

\section{References}

American Psychiatric Association (Ed.) (1994) Diagnostic and Statistical Manual of Mental Disorders- fourth edition. Washington, DC: American Psychiatric Association

Barkham, M., Mellor-Clark, J., Connell, J., and Cahill, J. (2006). A core approach to practice-based evidence: a brief history of the origins and applications of the CORE-OM and CORE system. Counselling and Psychotherapy Research, 6(1): 3-15.

Beck, A.T., Ward, C.H., Mendelssohn, M.J. and Erbaugh J. (1961) 'An inventory for measuring depression'. Archives of General Psychiatry, 4:561-571

Beck, A.T., Steer, R.A., Brown, G.K. (1996) Manual for Beck Depression Inventory II (BDI-II). San Antonio, TX: Psychology Corporation

Bledsoe, S.E., and Grote, N.K. (2006) 'Treating depression during pregnancy and post-partum: A preliminary meta-analysis'. Research on Social Work Practice. 16(2): 109-20.

Chambless, D.L. and Hollon, S.D. (1998) Defining Empirically Supported Therapies. Journal of Consulting and Clinical Psychology, 66(1): 7-18

Constantino, M.J., Arnkoff, D.B., Glass, C.R., Ametrano, R. M. Smith, J.Z. (2011) 'Expectations', Journal of Clinical Psychology: In Session. 67(2): 184-192

Connell, J. \& Barkham, M. (2007). CORE-10 User Manual, Version 1.1. CORE System Trust \& CORE Information Management Systems Ltd

Cuijpers, P., Andersson G., Donker T. and van Straten, A. 'Psychological treatment of depression: Results of a series of metaanalyses', Nordic Journal of Psychiatry, 65: 354-364 
Elliott, R. (2001). Hermeneutic single case efficacy design (HSCED): An overview. In K.J. Schneider, J.F.T. Bugental \& J.F. Fraser (eds.), Handbook of Humanistic Psychology (pp315-324), Thousand Oaks, CA: Sage.

Elliott, R. (2002) Hermeneutic Single-Case Efficacy Design. Psychotherapy Research, 12(1): 1-21

Elliott, R., Mack, C., \& Shapiro, D. (1999). Simplified Personal Questionnaire Procedure. (On-line). Available:

http://www.experiential-researchers.org/instruments/elliott/PQ

Procedure.doc Downloaded 25 January 2012

Elliott, R., Partyka, R., Alperin, R., Dobrenski, R., Wagner, J., Messer, S.B.,Watson, J.C. and Castonguay, L.G.(2009) 'An adjudicated hermeneutic single-case efficacy design study of experiential therapy for panic/phobia'. Psychotherapy Research, 19(4-5): 543-557

Fetsch, R. J., and Sprinkle, R. L. (1982) 'Stroking treatment effects on depressed males', Transactional Analysis Journal, 12(3): 213-7

Iwakabe, S. \& Gazzola, N. (2009) From single-case studies to practice-based knowledge: aggregating and synthesizing case studies. Psychotherapy Research, 19, 601-611

Jacobson, N. S., \& Truax, P. (1991). Clinical significance: A statistical approach to defining meaningful change in psychotherapy research. Journal of Consulting and Clinical Psychology, 59: 12-19

Llewelyn, S. (1988) Psychological therapy as viewed by clients and therapists. British Journal of Clinical Psychology, 27, 223-238.
McLeod, J. (2010). Case Study Research in Counselling and Psychotherapy. London: Sage

Miller, R.B. (2011) 'Real Clinical Trials (RCT) - Panels of Psychological Inquiry for Transforming Anecdotal Data into Clinical Facts and Validated Judgments: Introduction to a Pilot Test with the Case of "Anna"' , Pragmatic Case Studies in Psychotherapy, 7(1): 6-36 (article available at: http://pcsp.libraries.rutgers.edu Downloaded $4^{\text {th }}$ March 2011)

Stephen, S and Elliott, R. (2011) "the Adjudicated Case Study Method. Pragmatic Case Studies in Psychotherapy, 7(1): 230-241 (article available at: http://pcsp.libraries.rutgers.edu) Downloaded 4th March 2011

Swift, J.K., Callahan, J.L. and Vollmer, B.M. (2011) 'Preferences', Journal of Clinical Psychology: In Session. 67(2): 155-165

van Rijn, B., Wild, C., and Moran, P. (2011) 'Evaluating the Outcomes of Transactional Analysis and Integrative Counselling Psychology within UK Primary Care Settings', International Journal of Transactional Analysis Research. 2(2): 34-43

Widdowson, M. (2012) 'TA Treatment of Depression - A Hermeneutic Single-Case Efficacy Design Study - "Peter" ', International Journal of Transactional Analysis Research. 3(1): 313

Zuroff, D.C., Koestner, R., Moskowitz, D.S., McBride, C. Marshall, M. and Bagby, R.M. 'Autonomous motivation for therapy: A new common factor in brief treatments for depression', Psychotherapy Research. 17(2): 137-147 